\title{
Pipeline Transportation of Heavy Oils, a Strategic, Economic and Technological Challenge
}

\author{
A. Saniere ${ }^{1}$, I. Hénaut ${ }^{1}$ and J.F. Argillier ${ }^{1}$ \\ 1 Institut français du pétrole, 1 et 4, avenue de Bois-Préau, 92852 Rueil-Malmaison Cedex - France \\ e-mail: armelle.saniere@ifp.fr - isabelle.henaulł@ifp.fr - j-francois.argillier@ifp.fr
}

\begin{abstract}
Résumé - Transport en conduite des bruts lourds, un défi stratégique, économique et technologique - En raison de réserves très abondantes situées principalement au Venezuela et au Canada, les bruts lourds représentent une abondante source d'énergie. Ils permettraient, en effet, non seulement de répondre aux besoins énergétiques qui ne cessent de crôtre mais aussi de diversifier les sources d'approvisionnement. Le présent article s'attache à établir un panorama géographique complet de ces produits et à répertorier les récents projets de production les concernant. Le succès de ces projets relève d'importants défis techniques tant au niveau du réservoir que du transport et du raffinage. Cet article traite particulièrement du transport. Les différentes techniques possibles sont décrites : le chauffage, la dilution, la mise en émulsion, la valorisation sur champ et la lubrification pariétale. Afin d'améliorer ces techniques, une étude expérimentale reliant les propriétés structurelles et rhéologiques des bruts lourds a été menée pour comprendre l'origine de la forte viscosité et y remédier.
\end{abstract}

\footnotetext{
Abstract - Pipeline Transportation of Heavy Oils, a Strategic, Economic and Technological Challenge - Because of very large reserves mainly located in Venezuela and Canada, heavy crude oils represent a significant energy supply. This article gives an overview of the geographical distribution of their resources and lists the recent projects of production. These projects have to face technological challenges in all phases of operation: reservoir, transportation and refining. The paper focuses on transportation, describing the different methods (heating, dilution, oil-in-water emulsion, upgrading and core annular flow). In order to improve them or develop new ones, a structural and rheological study was undertaken to appraise the origin of the high viscosity and counteract its effect.
} 


\section{INTRODUCTION}

With the combination of an increase of world energy demand and the decline of conventional oils, heavy crude oils are usually presented as a future relevant hydrocarbons resource [1]. The aim of this paper is to examine to what extent these petroleum products can be regarded as a reliable energy supply. Two aspects have been considered: the economic and technical ones. The economic aspect is presented in the first part of the paper. After a brief definition of heavy crude oils, we give an overview of the geographical distribution of their resources and production. Part 1 also deals with the environmental issues associated with their exploitation. The technical aspect, which constitutes the second part of the paper, focuses on pipeline transportation that is particularly challenged by the high viscosity of heavy oils. The main classical methods found in literature are described. They include: heating, dilution, oil-in-water systems, core annular flow and partial up-grading. In order to improve the flow properties of heavy crude oils, a study was undertaken at IFP to appraise the origin of the viscosity and counteract its effect. The main results are summarized in the last parts of the paper followed by an example of how these results can contribute to lower the viscosity of heavy oils. The link between the morphology of heavy oils and their rheology will be explained in more detail through the associated articles in this issue.

\section{STRATEGIC AND ECONOMIC INTEREST OF HEAVY OIL EXPLOITATION}

With an ever growing population having a better level of life, energy consumption is projected to increase year after year: energy forecasts made by a number of prominent organisations, including the US Department of Energy, the

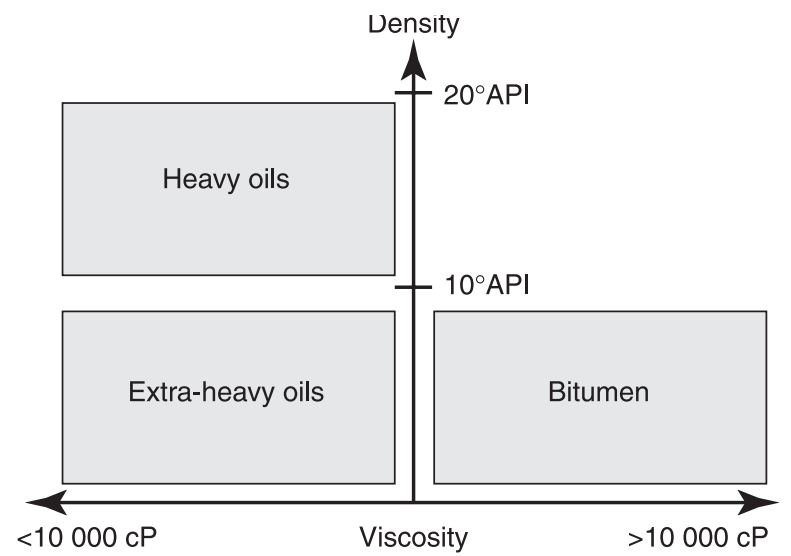

Figure 1

Heavy, extra-heavy oils and bitumen.
International Energy Agency (IEA) and the World Energy Council, all agree in that respect. According to the IEA's base scenario, world demand for primary energy should rise $20 \%$ by 2010 and $66 \%$ by 2030 , for an average growth rate of $1.7 \%$ a year. To cover this increase in world energy demand, it will be necessary to mobilise all energy resources, and hydrocarbons will continue to play a very prominent part in meeting world energy requirements (65 versus $62 \%$ today).

To meet these needs, heavy crudes, given the magnitude of their the resources, will play a more and more significant role. According to IEA, they will represent $15 \%$ of the growth of oil supply between 2000 and 2030. Nowadays, the heavy, extra-heavy oils and bitumen represent a huge amount of hydrocarbon resources but only a little share of the worldwide oil production. To understand the strategic importance of these crudes, it should be remembered that they are liable to nearly double the current proved oil reserves. Recently the US Energy Information Administration took oil sand reserves into account for its Canadian reserves evaluation: Canada thus became the second country with the highest oil reserves, just behind Saudi Arabia.

Heavy crudes which often result from a bacterial oxidation of conventional oils inside the reservoir rock, have different physical and chemical properties, generally degraded: they have much higher viscosity, higher heavy metals and higher sulfur and nitrogen contents.

Different categories of heavy crude are usually defined according to their density (Fig. 1):

- the heavy oils, the $\mathrm{API}^{\circ}$ of which is between 10 and 20 ;

- the extra-heavy oils and bitumen, the $\mathrm{API}^{\circ}$ of which is less than 10 (the "in situ" level of viscosity makes the distinction between extra-heavy oils and bitumen).

A fourth category does exist: oil shale. In this category, reservoir rock and source rock are the same because the oil has not migrated. Permeability is practically zero and exploitation is only possible with mining technologies.

These specific properties imply specific advanced technical solutions throughout their exploitation, from production, to transport and refining. Moreover, due to the huge reserves, development projects are long term ones, which implies specific investment, much higher than for conventional oil. Finally, extra-heavy oil and bitumen have a specific geographical distribution, independent from the Middle East and from OPEC quotas.

\subsection{Huge Reserves}

\subsubsection{Volumes in Place}

The identified volumes in place of heavy oil, extra-heavy oil and bitumen are estimated at about $4800 \mathrm{Gbbl}$, that is to say the equivalent of the remaining resources in place of conventional oils discovered until now. Few of those heavy 


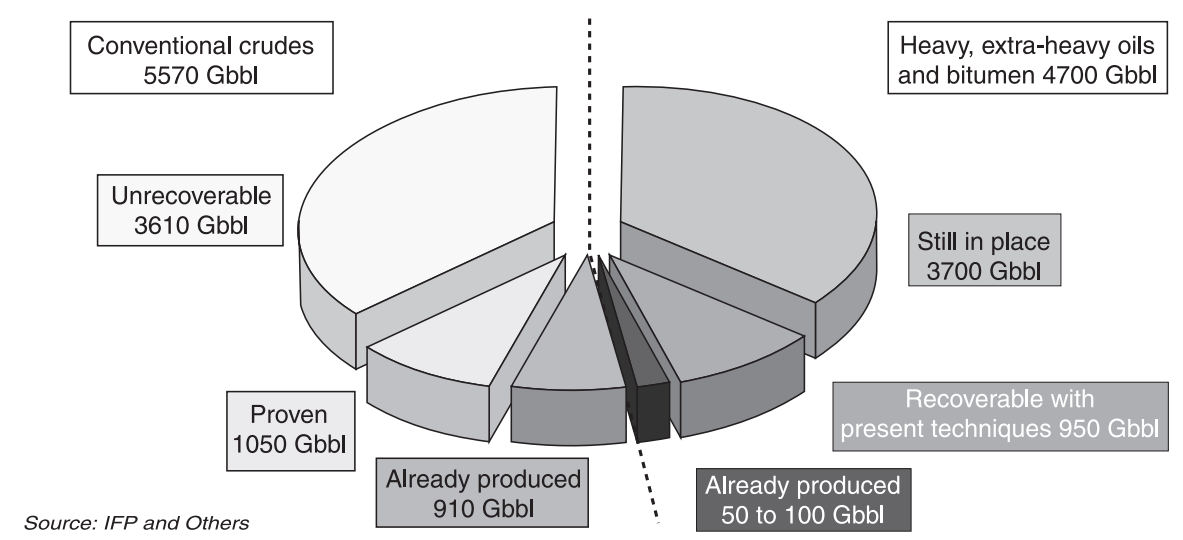

Figure 2

Distribution of identified petroleum resources in 2003.

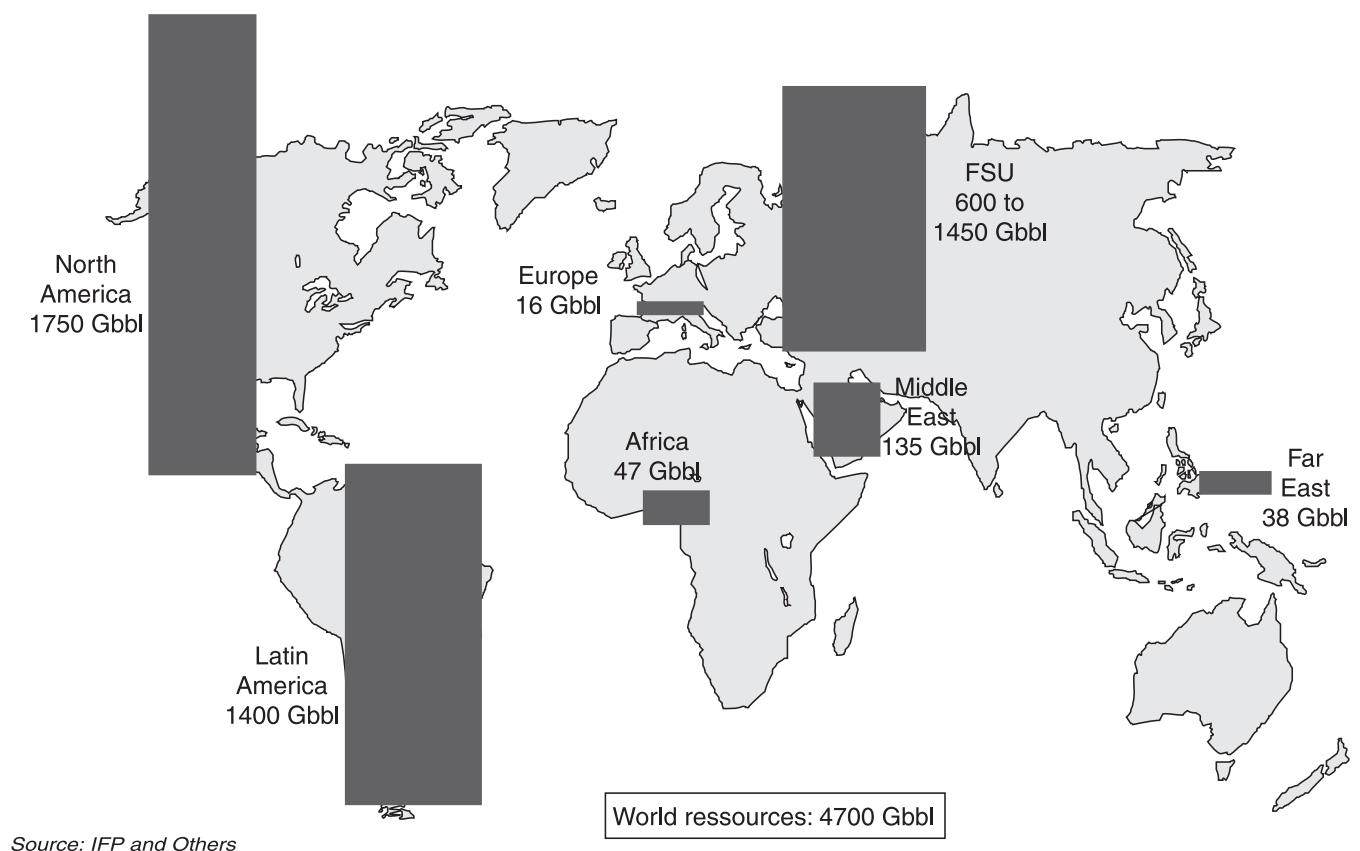

Figure 3

Geographical distribution of heavy, extra-heavy oils and bitumen resources.

crude resources have already been produced, only 1 to $2 \%$ (Fig. 2).

About $87 \%$ of those resources are represented by tar sands and bitumen in Canada, extra-heavy oils in Venezuela and heavy oils in Russia (Fig. 3). The resources in place in the Orinoco Belt in Venezuela are estimated at $1200 \mathrm{Gbbl}$ and those of bitumen in Canada at about $1700 \mathrm{Gbbl}$. In recent years, more and more information has been available concerning the Former Soviet Union Countries. According to different sources, it seems that 600 to $1300 \mathrm{Gbbl}$ of heavy oil and bitumen resources are located in Russia. We will focus on the most commercially advanced heavy hydrocarbons, that is to say those in Venezuela and Canada.

\subsubsection{Recoverable Resources}

Global technically recoverable resources are evaluated at $1000 \mathrm{Gbbl}$, i.e. the equivalent of the proven reserves of conventional oils. 50 to $100 \mathrm{Gbbl}$ have already been produced. 250 to $300 \mathrm{Gbbl}$ are recoverable in Canada and $300 \mathrm{Gbbl}$ in 
the Orinoco Belt in Venezuela. Recovery factors could be very different depending on the production method. In Venezuela, cold production allows a recovery rate between 5 and $10 \%$ and even $25 \%$ in the next decades. In Canada, the recovery rate ranges from 5 to $15 \%$ for in situ production and from 80 to $90 \%$ for the mining exploitation. Some estimates are that with the Steam Assisted Gravity Drainage (SAGD) method, recovery factors could reach $60 \%$.

\subsubsection{A Strategic Geographical Distribution}

Heavy oils, extra-heavy oils and bitumen are of a high strategic importance for OECD countries in terms of diversification of oil supply and enhancement of supply security. In fact, most of them are located outside the Middle East. With the ever increasing importance of this region in terms of oil reserves and production, heavy crude will become more and more attractive for western countries: exploitation of heavy crude will reduce the potential pricing power of the leading conventional oil producers. The September $11^{\text {th }}$ terrorist attacks intensified the energy supply concerns in the United States and the Canadian oil sands have been identified by the two governments as a "secure and strategic source of hydrocarbons".

\subsection{A Fast Growing Production}

Considering the quantity of the resources, the production of crude oil from heavy, extra-heavy crude and bitumen remains weak (Fig. 4). In 2003, it can be estimated at $5.5 \mathrm{Mbbl} / \mathrm{d}$, which represented only $7 \%$ of total world crude oil production which was estimated at $76.9 \mathrm{Mbbl} / \mathrm{d}$. In 1995, the production was $4.1 \mathrm{Mbbl} / \mathrm{d}$, that is to say, an increase of $25 \%$ of the heavy crude oil production in 9 years. At the same time, the total crude oil production increased by only $13 \%$. The exploitation of heavy crude remains concentrated; at present, the main producers, Mexico, Venezuela, Canada and the United States provide $60 \%$ of all commercialized volumes. Mexico, which is by far the biggest producer, with $2.3 \mathrm{Mbbl} / \mathrm{d}$, produces mainly heavy oil.

Production of crude from extra-heavy oil and bitumen was $1.4 \mathrm{Mbbl} / \mathrm{d}$ in 2003 (1.8\% of the world oil production), split approximately between Canada (2/3) and Venezuela (1/3). Today, extra-heavy oil and bitumen represent $87 \%$ of heavy crude resources but only $25 \%$ of production but this situation will change rapidly in the coming years and their production will sharply increase if the projects planned in Venezuela and Canada are accomplished.

\section{Projects Update}

\section{- In Canada}

$20 \%$ of the recoverable resources of bitumen are located at a shallow depth and can be exploited using mining technologies. This production method currently provides $53 \%$ of the Canadian bitumen and tar sand production $(558000 \mathrm{bbl} / \mathrm{d}$ in 2003). This industry is dominated by two companies, Syncrude and Suncor who both are conducting major

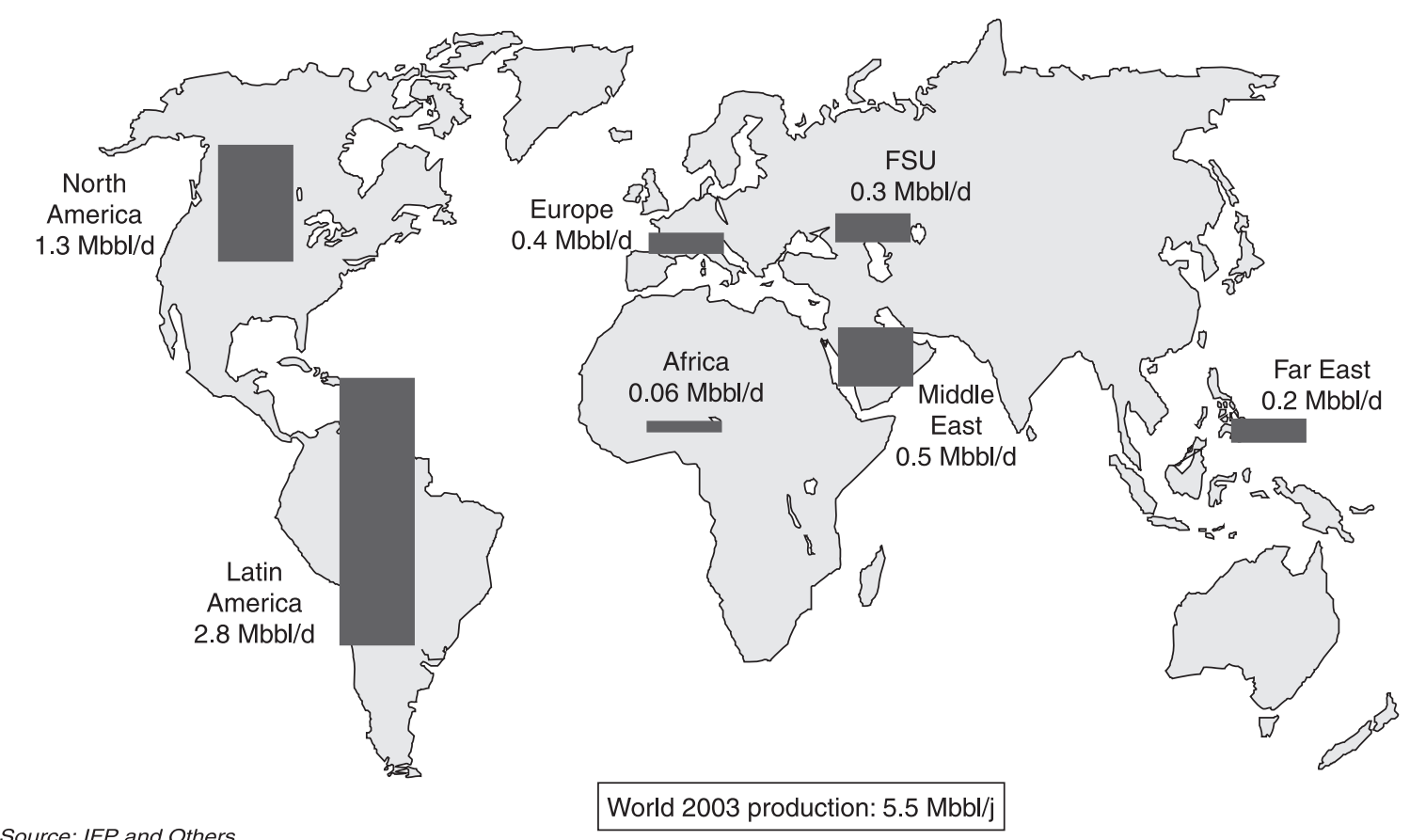

Source: IFP and Others

Figure 4

Geographical distribution of heavy, extra heavy oils and bitumen production. 
projects to increase their bitumen output. In 2003, Suncor produced about $225000 \mathrm{bbl} / \mathrm{d}$ with mining methods. With its ongoing Project Millenium, the company's production should reach $325000 \mathrm{bbl} / \mathrm{d}$ in 2010. Syncrude, which produced $248000 \mathrm{bbl} / \mathrm{d}$ in 2003, forecasts to double production in 2010 thanks to its "Syncrude 21" project.

These bitumen are upgraded in the production site and sold in the form of synthetic crude oil with an $\mathrm{API}^{\circ}$ between 29 and 36.

In 2007, the 5 projects planned should all be running and the total production of synthetic crude should reach 1.4 to 1.6 $\mathrm{Mbbl} / \mathrm{d}$ in 2010.

In the field of "in situ" production (i.e. recovery by petroleum methods), more than thirteen projects, currently underway or being studied, are expected in the coming years. In 2003, in situ production of extra-heavy oil and bitumen in Canada was $385000 \mathrm{bbl} / \mathrm{d}$. It could reach $1.2 \mathrm{Mbbl} / \mathrm{d}$ in 2010. In such projects, the extra-heavy oil is blended with a lighter, less viscous hydrocarbon (diluent) and sold as "bitumen blend" with an $\mathrm{API}^{\circ}$ of 21.

All together, more than 21 Canadian projects for the exploitation of tar sands and bitumen have been developed or are about to be developed. They will represent, if accomplished, a production of $1.6 \mathrm{Mbbl} / \mathrm{d}$ of synthetic crude and $1 \mathrm{Mbbl} / \mathrm{d}$ of bitumen blend in 2010, that is to say, the 2002 Canadian heavy oil and bitumen production should be multiplied by a factor of 2.6.

\section{- In Venezuela}

During the last ten years, joint-ventures (JV) involving major international oil companies have proposed or studied integrated projects to develop and exploit extra-heavy oil resources in the Orinoco Belt. Four extra-heavy oil projects are currently underway and two others have been submitted to the authorities. They all include transportation of the heavy crude by pipeline through dilution to an upgrader on the Coast at San Jose. There, the crude is more or less upgraded depending on the project: in the Sincor and Hamaca projects, extra-heavy crude is upgraded to a $26-32 \mathrm{API}^{\circ}$ crude which is then exported. In the Petrozuata and Cerro Negro projects, the crude is only partially upgraded and then exported to specific United States refineries. All the JVs are contracted for 35 years.

Two other projects are being studied by the government and, if the six projects are accomplished, about $950000 \mathrm{bbl} / \mathrm{d}$ of extra-heavy crude could be extracted from the Orinoco subsurface in 2015. This would allow some $850000 \mathrm{bbl} / \mathrm{d}$ of synthetic crude to be marketed that same year, which represents 3 times the present output.

Another way for the State-owned company PDVSA to valorize the huge reserves of extra-heavy oil lying in the underground of the country is the development of a product called ORIMULSION $^{\mathrm{R}}$. It is an emulsion made up of $70 \%$ bitumen and $30 \%$ water and marketed as a fuel for power generation in competition with residual fuel oil and coal. It is sold under long-term supply contracts to utilities in Japan, Italy, Denmark, Canada and, since May 2003, in South Korea. PDVSA's subsidiary Bitor, in charge of the commercialization of the product, began, at the end of 2002, the construction of a new production plant, capacity of which should be $6.5 \mathrm{Mt} / \mathrm{y}$. It should be operating mid 2004 and will allow the present ORIMULSION $^{\mathrm{R}}$ production to be multiplied by a factor of 2 . Another production plant should be constructed in association with Chinese companies. If those two projects are accomplished, the production of ORIMULSION ${ }^{\mathrm{R}}$ should be about $18 \mathrm{Mt} / \mathrm{y}$, that is to say, three times the 2001 production ( $2 \mathrm{Mt}$ ).

If all the projects planned in Venezuela and Canada are accomplished, a large nonconventional supply will be put on the market around 2010 (Fig. 5). In fact, the production of extra-heavy oil and bitumen from Venezuela and Canada will reach $3.1 \mathrm{Mbbl} / \mathrm{d}$ in 2010 and 4.4 in 2015, equivalent to 3 to 4 times their 2003 output. At the same time, the total crude oil production growth estimates are $20 \%$. The share of extraheavy oil and bitumen in the total oil production will thus increase to about 8-9\% in 2010.

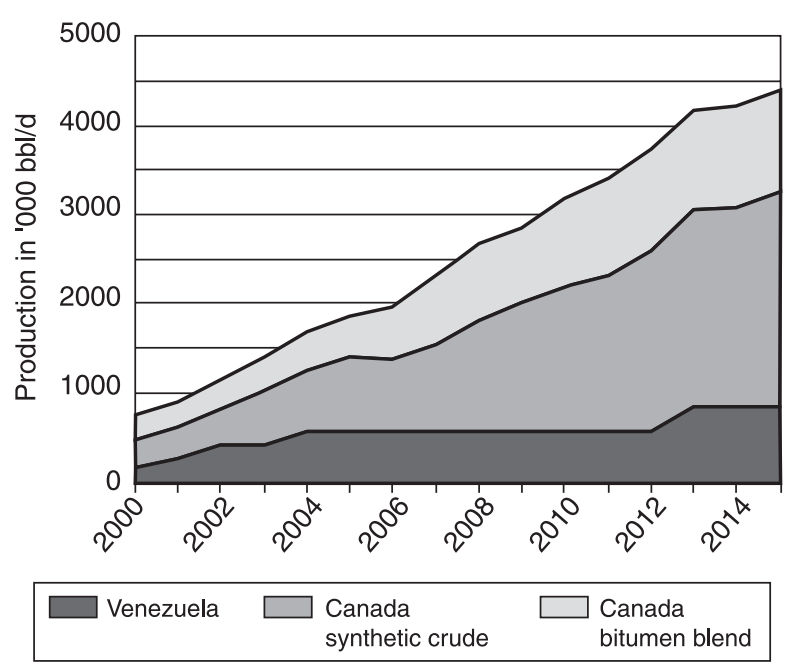

Source: IFP, PDVSA, EIG and Others

Figure 5

Production forecast for Canada and Venezuela.

\subsection{Investment, Costs and Economic Interests of Heavy Crude}

As we have seen concerning the ongoing projects, exploitation of extra-heavy oils and bitumen involves huge investments. In Venezuela, they amount to about $16 \mathrm{G} \$$, and in Canada, total investment for the mining and in situ production projects will 
reach $60-70 \mathrm{G} \$$. To have an idea of the capital intensity those projects involve, a comparison of the amount of investment to the plateau production level can be made: the capital intensity is about $20000 \$ / \mathrm{b} / \mathrm{d}$ in Orinoco; in Canada, it ranges from 24000 to $28000 \$ / \mathrm{b} / \mathrm{d}$ for $S A G D$ production and from 24000 to $30000 \$ / \mathrm{b} / \mathrm{d}$ for mining exploitation. For comparison, the capital intensity for deep offshore oil is about $12000 \$ / \mathrm{bbl} / \mathrm{d}$. Heavy oil exploitation is thus on average twice as capital intensive as the exploitation of conventional oil.

Technical costs per barrel (development, production and upgrading costs) for extra-heavy oil and bitumen have drastically decreased over the last twenty years. For mining exploitation in Canada, they were $25-30 \$ / b$ in the beginning of the eighties and are now at the level of 11-20 $\$ / \mathrm{b}$. For in situ production, it depends on the recovery methods: for cold production as in Venezuela, they are between 7 and $10 \$ / b$ and in Canada, where steam assisted recovery methods are often necessary, they range from 10 to $20 \$ / \mathrm{b}$. Certain companies announce that they can have a $14 \%$ return on investments with a West Texas Intermediate (WTI) price at $20 \$ / b$, which is a reasonable level. The price of the syncrude produced in Canada is sold with a down-quote of 1 to $2 \$ / b$ relating to WTI, but in Venezuela, the Zuata Sweet produced by the Sincor project is sold at the price of Brent $+0.5 \$ / b$, due to its very low sulfur content, about $0.2 \%$.

One major advantage of the extra-heavy oil and bitumen ongoing projects is that due to the amount of resources involved, the exploitation is a long term one: in Orinoco for example, production of the four ongoing projects should last 35 years. That allows both States and oil companies to secure a certain amount of oil revenues for a long period of time. Moreover, long term projects have the advantage of being more independent from oil price fluctuation than short term ones. In fact, the decision to launch the Sincor project in Orinoco for example was taken by Total in 1998, when the oil price was particularly low.
Another point is that, in Venezuela, the synthetic crude from heavy oil is considered as refined oil and is therefore not submitted to OPEC quotas contrary to the country's production. In both Canada and Venezuela, the syncrude produced is in direct competition with light conventional crude on the international market. In other words, extra-heavy oil and bitumen contribute to minimize the growth of the worldwide production under OPEC's control.

\subsection{Transportation Methods and their Relative Importance}

There are five different transportation methods. The main ones are dilution and partial upgrading which are often associated on a same project (Fig. 6).

In the partial upgrading method, the heavy crude is upgraded into a lighter one such as cold "Syncrude". As seen earlier, that method is applied in Canada where $588 \mathrm{Mbbl} / \mathrm{d}$ of synthetic crude is produced for export. There, the upgrading unit is located on the production site: the produced coke is stored in the open mine and the synthetic crude is transported to United States refineries.

The four projects in the Orinoco Belt use that method to export the extra-heavy oil produced. In 2003 about $434 \mathrm{Mbbl} / \mathrm{d}$ of Syncrude where produced in the country.

Dilution can be used in two different ways, depending on whether the diluent is recycled or not:

- In Canada, in projects exporting bitumen blend, the diluent is not recycled and the bitumen + diluent blend is sold. In 2003 in Canada, about $385 \mathrm{M} / \mathrm{j}$ of bitumen blend were produced. That solution depends on availability and price of the diluent. The most common diluent currently used is a very light natural gas condensate $\left(\mathrm{C}_{5}+\right.$ or "Pentane Plus") which is a by-product of natural gas processing, or a light hydrocarbon. A diluent typically constitutes

\begin{tabular}{|c|c|c|c|c|c|}
\hline & Heating & Dilution & Upgrading & Emulsion & Annular flow \\
\hline $\begin{array}{l}\text { Required pipe } \\
\text { diameter }\end{array}$ & Normal & Larger & Normal & Larger & Normal \\
\hline Corrosion & Potential & None & None & Potential & Potential \\
\hline $\begin{array}{l}\text { Additional } \\
\text { investments }\end{array}$ & $\begin{array}{l}\text { Normal } \\
\text { (heaters) }\end{array}$ & $\begin{array}{c}\text { High } \\
\text { (parallel diluent system) }\end{array}$ & $\begin{array}{c}\text { High } \\
\text { (field refinery) }\end{array}$ & $\begin{array}{c}\text { Normal/high } \\
\text { (supply system) }\end{array}$ & $\begin{array}{c}\text { Normal/high } \\
\text { (apply system) }\end{array}$ \\
\hline $\begin{array}{l}\text { Environmental } \\
\text { problems }\end{array}$ & $\begin{array}{l}\text { Electricity } \\
\text { source }\end{array}$ & $\begin{array}{c}\text { No } \\
\text { specificity }\end{array}$ & $\begin{array}{c}\text { No } \\
\text { specificity }\end{array}$ & $\begin{array}{c}\text { Water } \\
\text { separation/treatment }\end{array}$ & $\begin{array}{l}\text { Water } \\
\text { treatment }\end{array}$ \\
\hline
\end{tabular}

Figure 6

Comparison of the transportation methods. 
$24-50 \%$ of the bitumen blend. However, light hydrocarbons suitable for dilution are costly and natural gas condensate is not readily available in large quantities. That is why certain companies recycle the diluent.

- In the four Orinoco projects in Venezuela, the diluent is used to transport the extra-heavy oil from the production site to the special upgrader on the coast, where it is separated and can be reused.

In Canada, the Muskeg River Mine built by Albian Oil Sands Energy Inc. is exploited in the same way: the bitumen is firstly diluted, then transported via the Corridor Pipeline System to a regional upgrader in Scotford where it is transformed into synthetic crude. The Corridor Pipeline System is a dual pipeline system transporting diluted bitumen to the Scotford upgrader and the diluent back to the mine.

Separating the diluent, building a separate diluent return pipeline and operating a separate pipeline is costly. One advantage, however, is that the method consumes less solvent than for bitumen blend exportation and is thus less subject to problems of availability and price of the solvent.

A third way to transport heavy oil is to heat the oil as the viscosity decreases very rapidly with increasing temperature. In Canada, projects that want to ship their products to a regional upgrader or major pipeline terminal without diluent will require a heated/insulated pipeline. Enbridge Pipeline has just constructed such a pipe for PetroCanada to ship bitumen from the MacKay River production site to Fort MacMurray where it is blended before being exported to the North American market. Terasen is also considering constructing such a line from Fort McMurray to Edmonton. That transportation method is also used worldwide in Africa and South America.

The other two ways to transport heavy oil which are oil in water emulsion and core annular flow, the last one remaining marginal. Oil in water emulsion is used in Venezuela to produce ORIMULSION ${ }^{\mathrm{R}}$. In this process the emulsion is not broken and used as such to feed power generation plants.

Concerning core annular flow, there have been only two industrial examples since 1970 and it seems that no project concerning that method is planned today except for oil sand hydrotransport as developped by Syncrude in Canada. It seems to raise a lot of technical issues and R\&D effort is still necessary.

\subsection{Environmental Issues Associated with Heavy Oil Exploitation}

Environmental concerns are among the major issues for the exploitation of extra-heavy oils and bitumen. Canadian oil sand operators must deal with local concerns about the disposal of huge volumes of tailings into giant sludge pounds and there is growing concern for water supply and treatment.

The main concern for extra-heavy oils and bitumen exploitation are $\mathrm{CO}_{2}$ emissions. A recent study realized in IFP( $^{(1)}$ underlines that all along the heavy, extra-heavy and bitumen pathway, $\mathrm{CO}_{2}$ emissions are 4 to 6 and even 10 times higher than in the conventional one, depending on the project (Orinoco type or steam injection type like in Canada). Moreover, the energy yield of projects such as those in the Orinoco region is about $89 \%$ and those with steam injection $86 \%$, meanwhile yields of conventional oil are close to $98 \%$ (Fig. 7). The study also underlines that technological innovation such as horizontal wells allows substantial improvements in terms both of $\mathrm{CO}_{2}$ emissions and energy yield.

(1) Évaluation des émissions de $\mathrm{CO}_{2}$ des filières énergétiques conventionnelles et non conventionnelles de production de carburants à partir des ressources fossiles, Georgia Plouchard, April 2001.

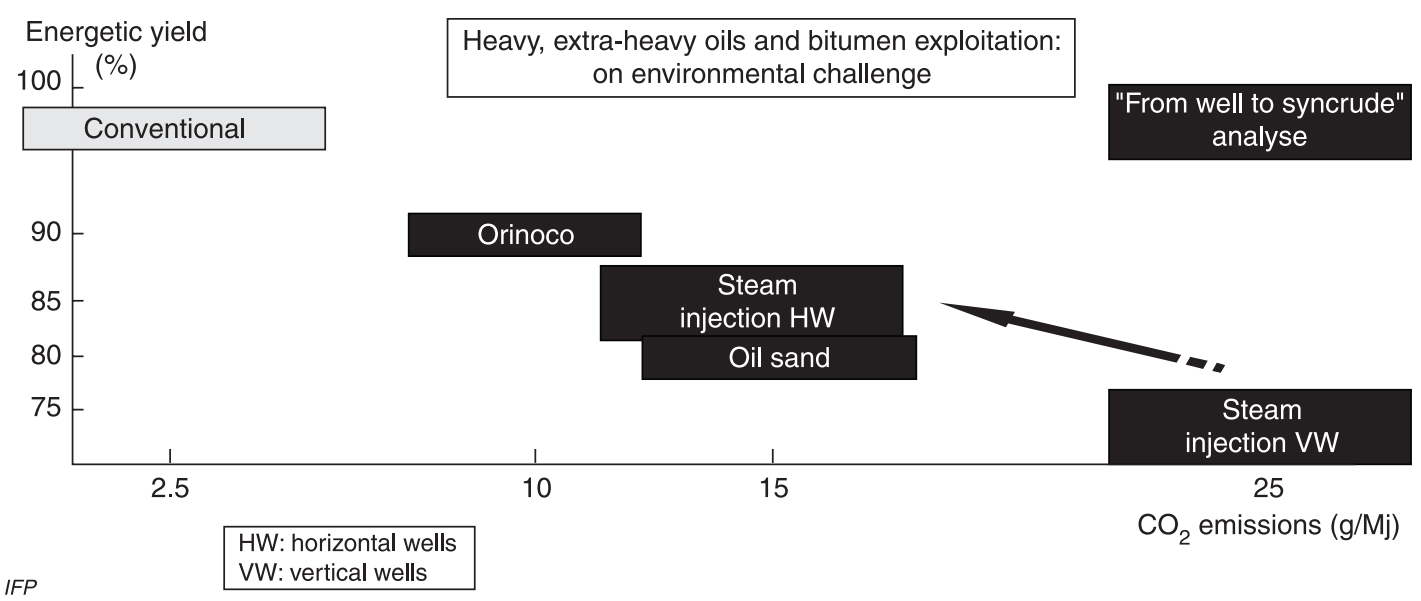

Source: IFP

Figure 7

Heavy, extra-heavy oils and bitumen exploitation: an environmental challenge. 
In that context, the Kyoto protocol is an issue for extra heavy oil and bitumen producers. Canada recently ratified the protocol, which means that the country accepts to reduce its $\mathrm{CO}_{2}$ emissions. At the same time, however, the present outlook on the extra-heavy oil and bitumen production in the country indicates a tripling between now and 2010. For producers, the Kyoto protocol ratification means an increase of the cost per barrel for synthetic crude of between 0.95 and 4.75 US\$ depending on how the $\mathrm{CO}_{2}$ credits are valued $(10$ or $50 \$ / t)$. In Venezuela, due to the "cold production" methods and the fact that operators have undertaken voluntary efforts to limit $\mathrm{CO}_{2}$ emissions (projects are more recent), the issue seems to be less crucial.

Due to the huge amount of their resources, their geographical distribution independent from the Middle East and the fact that they are not submitted to OPEC quotas, heavy crudes are of an ever greater strategic interest for western countries to secure their oil supply. That explains why there are so many projects on them, even if their exploitation is very capital intensive and technical costs inferred are higher than those for conventional oil. In the last ten years, a lot of technical innovations have been made, allowing costs to be lower and lower and even if they stay higher than those for conventional oil, heavy crude exploitation is nowadays highly profitable. Technical challenges still remains all along the pathway of heavy oil exploitation, from enhancing recovery rates to improving upgrading techniques. Beside those issues, research and development needs to concentrate particularly on enhancing energy yield and reducing environmental problems, especially water treatment and $\mathrm{CO}_{2}$ emissions. This is essential for the heavy oil contribution to present sustainable development concerns.

\section{TRANSPORTATION METHODS}

Due to their very high viscosity, heavy crude oils cannot be transported with conventional pipelines and require additional treatments. These solutions consist either in reducing the viscosity (heating, dilution, oil-in-water emulsion, upgrading) or in lowering the friction in the pipe (core annular flow). Each of them is briefly described below.

\subsection{Heat Treatment}

As viscosity decreases very rapidly with increasing temperature, heating is an attractive method for improving the flow properties of heavy crude oils. It is always cited as a possible process to reduce the viscosity of heavy oils [2-6]. A famous example is the Alyeska pipeline in Alaska which transports crude oil at approximately $50^{\circ} \mathrm{C}$. However, the design of a heated pipeline is not easy as it involves [3] many considerations: expansion of the pipelines, number of pumping/heating stations, heat losses etc. Other significant issues are the high costs and the greater corrosion rate of the internal pipe due to

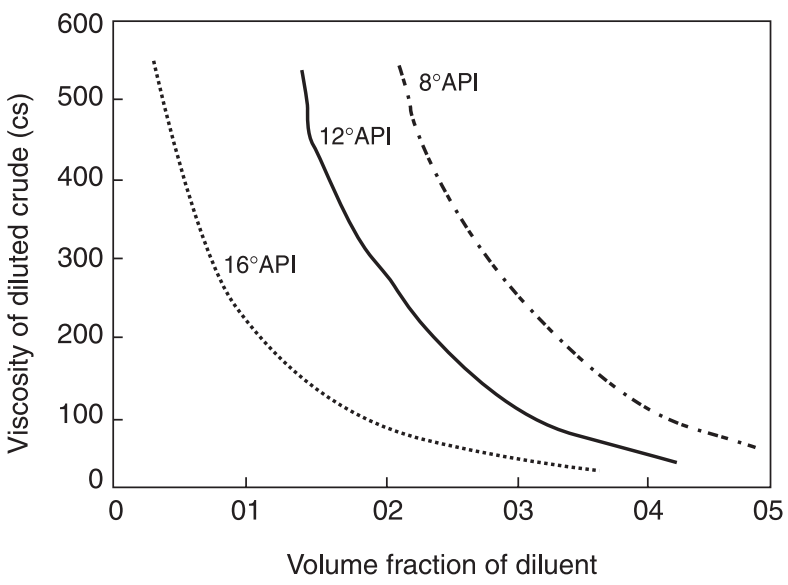

Figure 8

Effect of dilution with condensate on crude oil viscosity for different API gravities [8].

the temperature. Moreover, a recent study [7] showed that heat treatment could induce changes in the colloidal structure of the crude oils and worsen their rheological properties.

\subsection{Dilution}

An advanced method of enhancing heavy crude oils transport is by blending them with a less viscous hydrocarbon such as condensate, naphtha, kerosene, light crudes. According to [3], there is an exponential relationship between the resulting viscosity of the mixture and the volume fraction of the diluent (Fig. 8), which makes dilution a very efficient method.

However, in order to attain acceptable limits for transportation, a fraction as high as $30 \%$ in volume of diluent is necessary and implies large pipeline capacity. Problems could also come from the availability of the diluent [9]. Recycling of diluent might be a solution but it requires a large investment to install an additional pipeline.

\subsection{Emulsion}

The emulsion method consists in dispersing the heavy crude oil in water in the form of droplets stabilized by surfactants, leading to an important reduction of viscosity. According to [10], a typical emulsion is composed of $70 \%$ crude oil, $30 \%$ aqueous phase and 500-2000 ppm of chemical additives. The resulting emulsion has a viscosity in the 50-200 $\mathrm{cP}$ range at pipeline operating conditions (Fig. 9) and is particularly stable. This method is applied in Venezuela with the commercialization of ORIMULSION ${ }^{\circledR}$ product [11], emulsion sold as a fuel for electric power plant. Recovering the crude oil for further processing implies breaking the emulsion and such a process is not available. Issues related to water recycling still have to be resolved. 


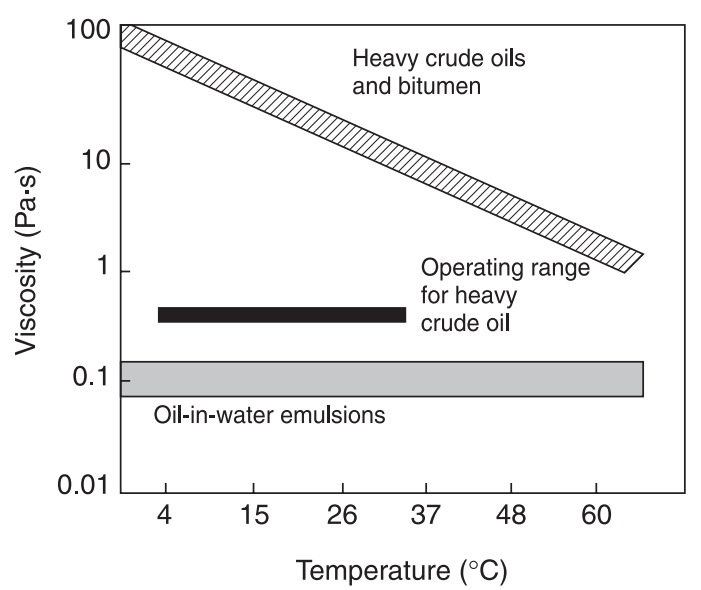

Figure 9

Reduction of viscosities of heavy crude oils and bitumen by conversion to oil-in-water emulsions, adapted from [2].

\subsection{Partial Upgrading}

This method consists in modifying the composition of heavy oils to make them less viscous. Upgrading technologies such as hydrotreating processes traditionally used in refineries, can be considered for this application. Suitable treatments of this kind were developed by ASVAHL, Association for the Valorization of Heavy Oils [8] (deasphalting process Solvahl, thermal treatment Tervahl process and catalytic hydrotreatment Hyvahl processes). Recent studies at IFP aim to associate these different processes to optimize the heavy crude conversion. The combination of hydrotreating and solvent deasphalting processes is particularly studied.

\subsection{Core Annular Flow}

The core annular mode flow can be an attractive method for the transportation of viscous crude oil. In this method of transportation, a water film surrounds the oil core and acts as a lubricant so that the pumping pressure necessary for the lubricated flow is comparable to the one for water alone. The water fractions are typically in the range of 10-30\%. Many theoretical studies, laboratory and field tests have been carried out [12-14] and have shown that the configuration of core annular flow applied to heavy oils is stable. However, only two industrial examples of this technology are known [3]:

- the $38.6 \mathrm{~km}$ Shell line from the North Midway Sunset reservoir to the central facilities at Ten Section (California), line that was operated during 12 years;

- the $55 \mathrm{~km}$ pipe from San Diego to Budare (Venezuela) used for transporting Zuata heavy crude oil (9.6 API $\left.{ }^{\circ}\right)$.
The main problem of that technology is that the oils tends to adhere to the wall, leading to restriction and an eventual blockage of the flow system. This kind of difficulty can be exacerbated during a shutdown operation allowing stratification of oil and water phases and requiring a large restart pressure.

\section{ORIGIN OF THE HIGH VISCOSITY OF HEAVY CRUDE OILS}

One main chemical characteristic of a heavy oil is its large content in asphaltenes. These molecules constitute a class of substances defined on the basis of their solubility in organic solvents: they are soluble in toluene but insoluble in alkanes such as $n$-pentane. Asphaltenes are the heaviest and most aromatic and polar fraction of a crude oil. These particular components are described as molecules composed of polycondensed aromatic rings carrying aliphatic chains that contain acid-base and polar groups at their edge. It is well recognized that thanks to these chemical characteristics, asphaltenes can self assemble through physical interactions and increase the viscosity of a medium in which they are added. Most of these studies were realized with simple organic solvents [15-18]. As these solvents are not as complex as heavy oils, we previously investigated the influence of asphaltenes in their natural environment by recombining deasphalted oil (maltenes) and various amounts of asphaltenes [19]. The main results of this experimental research are summarized below.

The rheological measurements realized on the mixtures of maltenes and asphaltenes revealed that above a critical concentration of asphaltenes $C^{*}$ these components dramatically increase the viscosity.

Small angle X-ray scattering (SAXS) studies performed on the same samples showed that this phenomenon is due to a structural change:

- when $C<C^{*}$ (dilute domain), the particles of asphaltenes behave as colloidal particles dispersed in oil. The structural parameter measured by SAXS can be considered as their radius of gyration $\mathrm{Rg}$.

- when $C>C^{*}$ (semi-dilute domain), the particles of asphaltenes overlap. In such a regime, the structural parameter is the correlation length $\xi$ which is indicative of the mesh size of the network formed by the asphaltenes.

The experimental data of both techniques are presented in Figure 10 which shows that the observed structural change is well correlated to an increase of viscosity, $\eta_{r}$.

A schematic representation of the ordered structure organized by particles of asphaltenes in heavy oils is given as a function of concentration (Fig. 11).

It can be noted that the original heavy crude oil contains $17 \%$ of asphaltenes and belongs to the semi-dilute domain. Its asphaltenes are overlapped and its viscosity is high. 


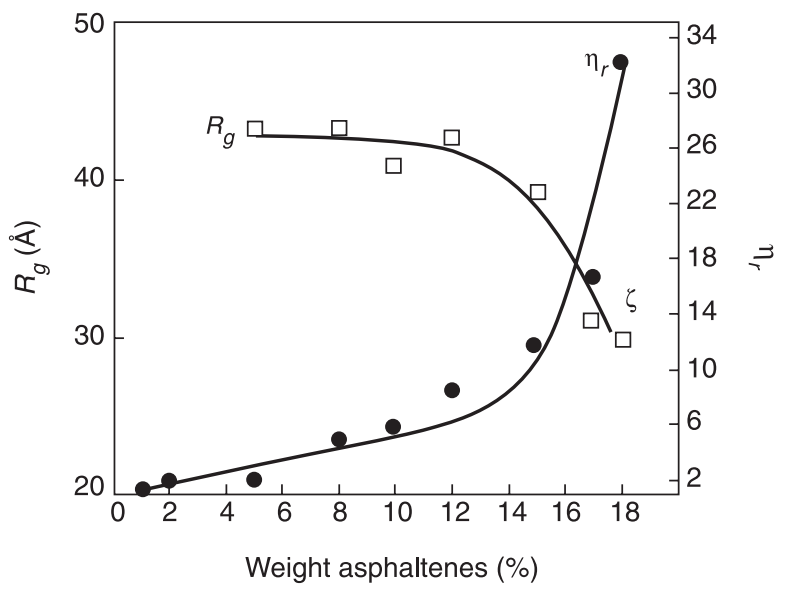

Figure 10

Rheological and structural experiments made on asphaltenes added to maltenes, $T=20^{\circ} \mathrm{C}$, [19].

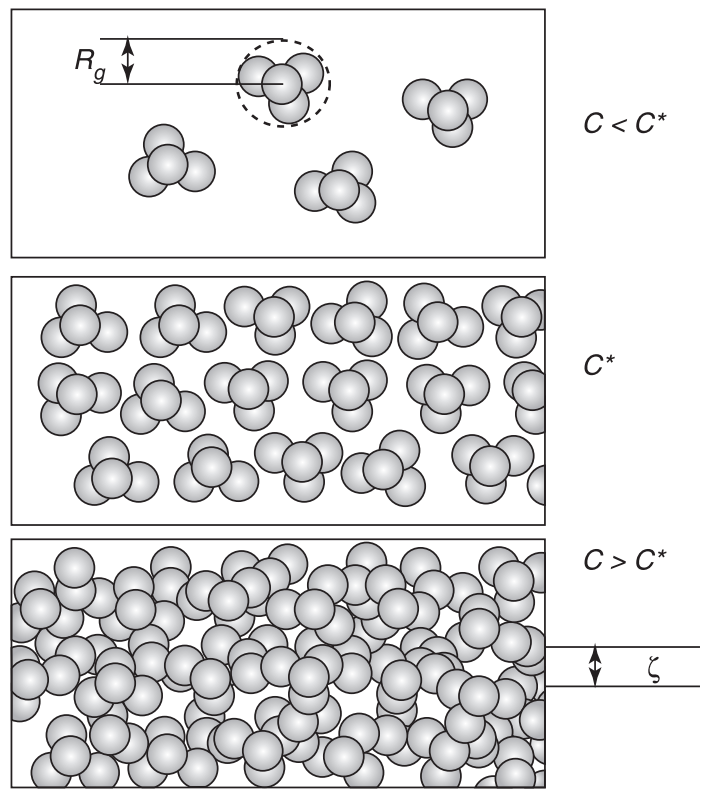

Figure 11

Schematic representation of asphaltenes association.

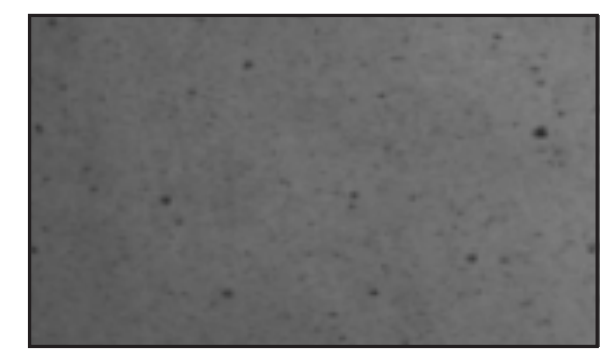

a)

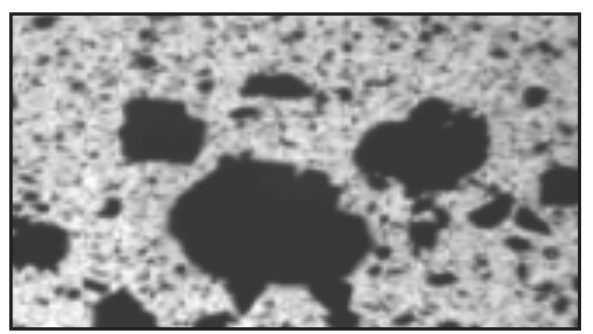

b)

\section{Figure 12}

Optical microscopy $(\times 40)$ of the colloidal crude oil (a) and its homologous slurry (b), $T=20^{\circ} \mathrm{C}$.

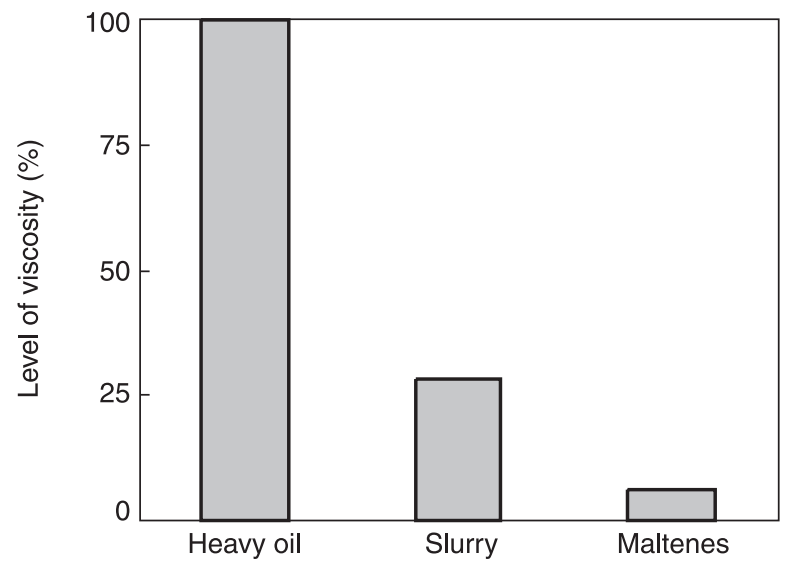

Figure 13

Flow curves of the colloidal crude oil and its homologous slurry, $T=20^{\circ} \mathrm{C}$.

\section{SLURRY TRANSPORTATION}

In the previous section of the paper, we have seen that heavy crude oils can be described as a colloidal suspension composed of a solute (asphaltenes) and a liquid phase (maltenes). We have shown that the asphaltenes inside a heavy oil develop a particular morphology, they are overlapped. Due to this overlapping, asphaltenes strongly contribute to the high viscosity of heavy oils. Therefore, we have suggested to counteract the effects of the overlapping by simply suppressing it. To do so, we have prepared samples of maltenes into which precipitated asphaltenes have been added after sieving (100-500 $\mu \mathrm{m})$ with a special procedure. These asphaltenes have been added to the maltenes at $40^{\circ} \mathrm{C}$ for 20 min under an appropriate mechanical stirring. Thanks to this procedure, we have checked by optical microscopy that the obtained samples are not colloidal as in the original crude but are of a slurry type with detectable solid particles over $1 \mu \mathrm{m}$ (Fig. 12). 

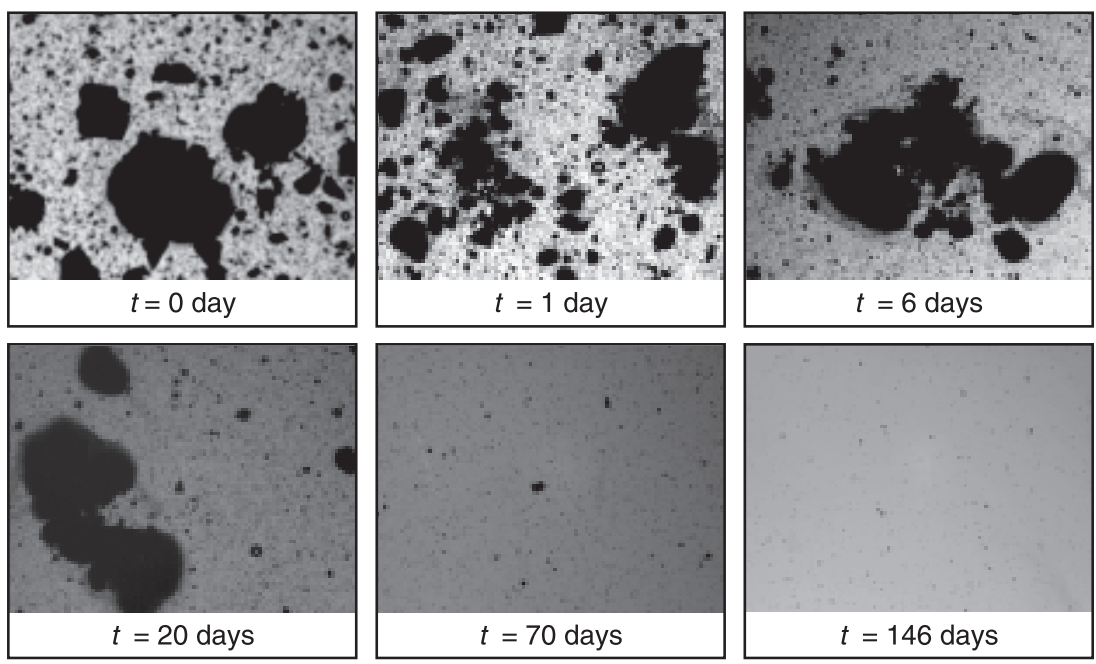

Figure 14

Evolution with time of the morphology of the $10 \%$ slurry sample, optical microscopy, $T=20^{\circ} \mathrm{C}$.

To observe the impact of this structural change on the level of viscosity, rheological tests were carried out on the original colloidal crude and its homologous slurry. They both contain $17 \%$ in weight of asphaltenes. Note that the heavy crude oil has been heated at $40^{\circ} \mathrm{C}$ during $20 \mathrm{~min}$ to be compared to the slurry independently of their thermal past. The results are presented in Figure 13.

It can be easily seen that the viscosity of the slurry is significantly lower than that of the colloidal heavy crude oil. This trend confirms that the overlapping of asphaltenes inside heavy oils is strongly responsible for their high viscosity. In fact, asphaltenes of the slurry sample are precipitated and occupy a much smaller volume than the deployed colloidal asphaltenes. The slurry sample and the heavy oil contain the same weight fraction but with a very different apparent volume fraction. It appears that one way to lower the viscosity of heavy oils is to diminish the apparent volume occupied by their asphaltenes. It can be noticed that the slurry sample, despite the presence of large particles, remains Newtonian and does not have a yield strength, which is quite unusual for slurry products [20,21].

In order to examine the feasibility of this method, several technical points had to be checked such as the stability of the slurry configuration with time, shear and temperature. Concerning the influence of shear, we observed that moderate shear rates such as the ones encountered in pipe flows do not affect the slurry morphology. This phenomenon has to be verified for higher shear rates such as the ones expected in pumping stations, valves etc. The stability of a slurry sample containing $10 \%$ of asphaltenes with time has been monitored concurrently by optical microscopy and rheology (Figs. 14 and 15).

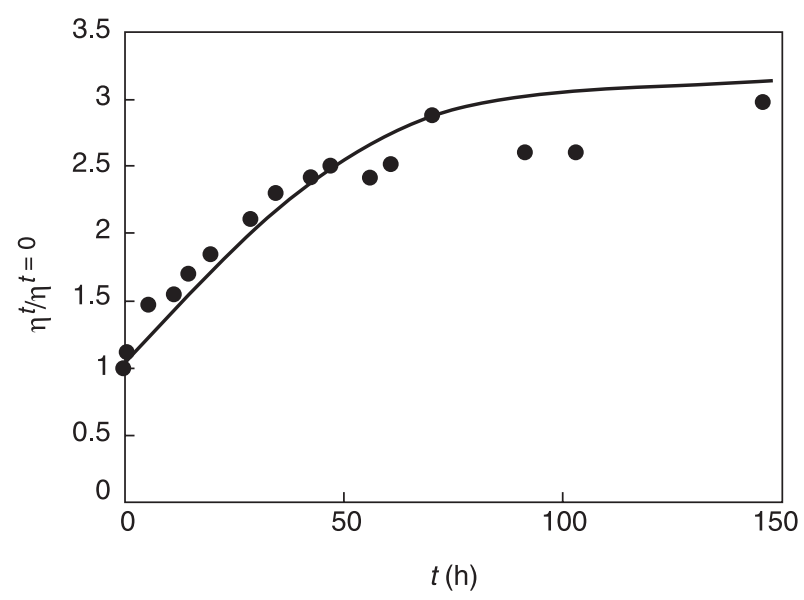

Figure 15

Evolution with time of the normalized viscosity of the $10 \%$ slurry sample, $T=20^{\circ} \mathrm{C}$.

The results show that the precipitated asphaltenes become progressively colloidal with time. This evolution is probably due to the thermodynamic equilibrium that promotes the colloidal state rather than the precipitated one. This transformation is quite slow and gives rise to a correlated increase of viscosity. These tests have been carried out at $20^{\circ} \mathrm{C}$ and have been repeated at higher temperatures $\left(30\right.$ and $\left.40^{\circ} \mathrm{C}\right)$. The experimental results show that the evolution from the precipitated state to the colloidal state is accelerated by a high temperature. These observations show that the slurry method is 
interesting but needs to be improved to lower even more the viscosity and to face higher temperatures. In this way, some studies are underway to adapt the procedure of preparation and to inert the precipitated asphaltenes so that they do not re-dissolve in maltenes. This work on slurry has been performed through a collaborative study with Total and was partly financially supported by the FSH (Fonds de Soutien aux Hydrocarbures).

\section{CONCLUSION}

Given the increasing world energy demand, heavy crude oils represent a significant energy supply that will play an important role. Here, we have seen that their resource are very large and mainly located in Canada and Venezuela allowing a diversification of oil supply. However, these petroleum products are known to present technical challenges in all phases of operation : reservoir, transportation, refining. This paper focuses on transportation issues and shows that various technical solutions and innovations are possible (heating, dilution, oil-in-water emulsion, core annular flow and upgrading). These different technologies need to be studied in more detail and to be optimized. A comparative analysis assessing the advantages and disadvantages of all of them will therefore be necessary. This paper also shows that the approach of appraising the origin of the high viscosity to counteract its effect is fruitful. In this context, the role of asphaltenes has been particularly documented, and now, attention will be paid to resins, the second highest molecular weight polar components of heavy oils.

\section{REFERENCES}

1 Lanier, D. (1998) Heavy oil - a major energy source for the $21^{\text {st }}$ century. $7^{\text {th }}$ Unitar Heavy Crude \& Tar Sands Int. no. 1998.039 Conf, Beijing, China.

2 Gerez, J.M. (1996) Heavy oil transportation by pipeline. International pipeline conference, 2, ASME.

3 Guevara, E., Gonzalez, J. and Nuñez, G. (1998) Highly viscous oil transportation methods in the Venezuela oil industry. Proceedings of the $15^{\text {th }}$ World Petroleum Congress, John Wiley and Sons, London, 495-501.

4 Meyer, R.F. (1998) World heavy crude oil resources. Proceedings of the $15^{\text {th }}$ World Petroleum Congress, John Wiley and Sons, London, 459-471.

5 Nunez, G.A., Rivas, H.J. and Joseph, D. (1998) Drive to produce heavy crude prompts variety of transportation methods. Oil \& Gas journal, Oct. 26, 59-67.
6 Yaghi, B. and Al-Bemani, A. (2002) Heavy crude oil viscosity reduction for pipeline transportation. Energy sources, 24, 93-102.

7 Evdokimov, I.N., Eliseev, D.Yu., and Eliseev, N.Yu. (2002) Negative viscosity anomaly in liquid petroleum after heat treatment. Chemistry and Technology of fuels and oils, 38, 3, 171-177.

8 Charlos, J.C., Courdec, J.L. and Page, J.F. (1988) Heavy oil processing, a synthesis of the ASVAHL results, in: E.C. $3^{\text {rd }}$ European community symposium on new technologies for the exploration and exploitation of oil and gaz resources, Proceeding, March 22-24, 2, E. Millich et al. eds, Luxembourg.

9 Crandall, G. and Wise, T. (1984) Availability of diluent may inhibit heavy oil exports. Canadian Petroleum, July-August.

10 Rimmer, D., Gregoli, A., Hamshar, J. and Yildivim, E. (1992) Pipeline emulsion transportation for heavy oils, in: Emulsions in the Petroleum Industry, American Chemical Society, 8, 295-312.

11 Layrisse, R. (1998) Viscous hydrocarbon-in-water emulsions. US Patent 4,795, 478.

12 Joseph, D., Bai, R., Chen, K.P. and Renardy, R., (1997) Core annular flows. Annual Review of Fluid Mechanics, 29, 65-90.

13 Joseph, D. and Renardy, Y. (1993) Fundamentals of Two Fluid Dynamics, Springer Verlag, New York.

14 Oliemans, R. and Ooms, G. (1986) Core annular flow of oil and water through a pipeline, in: Multiphase Science and Technology, Hewitt, G.F., Delhaye J.M. and Zuber, N. editors, 2, Hemisphere Publishing Corp., Washington.

15 Acevedo, S., Ranaudo, M.A, Pereira, J.C., Castillo, J., Fernández, A., Pérez, P. and Caetano, M., (1999) Thermooptical studies of asphaltene solutions: evidence for solvent-solute aggregate formation. Fuel, 78, 9, 997-1003.

16 Reerink, H. and Lijzenga, J. 1973) Journal of the Institute of Petroleum, 59, 569, 211-222.

17 Sheu, E.Y., Storm, D.A. and de Tar, M.M. and (1991) Asphaltenes in polar solvents. Journal of Non-Crystalline Solids, 131-133, 341-347.

18 Yudin, I.K., Nikolaenko, G.L., Gorodetskii, E.E., Kosov, V.I, Melikyan, V.R, Markhashov, E.L, Frot, D. and Briolant, Y. (1998) Mechanisms of asphaltene aggregation in toluene-heptane mixtures. Journal of Petroleum Science and Engineering, 20, 3-4, 297-301.

19 Hénaut, I., Barré, L., Argillier, J.F., Brucy F. and Bouchard R. (2001) Rheological and structural properties of heavy crude oils in relation with their asphaltenes content. Oilfield Chemistry, International Symposium of the Society of Petroleum Engineers, SPE 65020, Houston, Feb. 13-16.

20 Shook, C.A. and Roco, M.C. (1991) Slurry Flow, Principles and Practice, Butterworth-Heinemann.

21 Wasp, E.J., Kenney, J.P. and Gandhi, R.L. (1979) Solidliquid flow slurry pipeline transportation, Trans. Tech. Publications, Clausthal, Germany.

Final manuscript received in September 2004 